\title{
O ARGUMENTO DA RESPONSABILIDADE: UM ENSAIO SOBRE O NÃO POSITIVISMO INCLUSIVO DE ROBERT AlEXY E OS BENS HuMANOS BÁSICOS
}

\author{
Alberto de Moraes Papaléo Paes ${ }^{\dagger}$ \\ JaCIEL DE Moraes PapalÉO PaES ${ }^{\dagger \dagger}$
}

RESUMO: No presente ensaio pretendemos analisar o conceito de Robert Alexy acerca do que vem a ser o Não Positivismo Inclusivo. Ao descrever a teoria do direito alexyiana pretendemos denunciar as opacidades do discurso relativista que ela acaba produzindo a partir da perspectiva da responsabilidade civil. Fazendo isto, pretendemos, por oportuno, indicar uma alternativa possível capaz de mitigar o relativismo dos discursos baseados no pressuposto de autonomia kantiana a partir de um revigoramento de Aristóteles e São Tomás de Aquino na obra de John Finnis. Apesar de discordarmos de algumas conclusões conservadoras do autor australiano sua metodologia analógica se torna uma possibilidade de objetivação do dano e inserção do interesse jurídico como critério validativo para compreensão da responsabilidade com os bens humanos básicos.

Palavras-Chave: Não-Positivismo; Responsabilidade; Bem Comum; Robert Alexy; John Finnis.

\footnotetext{
${ }^{\dagger}$ Professor de Direito Constitucional da Universidade da Amazônia (UNAMA), de Hermenêutica Jurídica e Direito Constitucional na Faculdade de Belém (FABEL) e de Direito Civil e Direito Constitucional no Centro Alternativo de Cultura (CAC), Doutorando em Direitos Humanos pela Universidade Federal do Pará (UFPA), Mestre e Bacharel em Direito pela UNAMA, com Extensão em "Direito Constitucional: Organização dos Poderes" pela Pontifícia Universidade Católica de São Paulo (PUCSP) e Advogado.

"† Professor da Universidade da Amazônia (UNAMA), da Faculdade de Belém (FABEL) e da Faculdade do Pará (FAP), Mestre e Especialista em Direito do Trabalho e Bacharel em Direito pela UNAMA e Bacharel em Economia pelas Faculdades Integradas Colégio Moderno (FICOM), Advogado e Procurador do Tribunal de Justiça Desportiva do Estado do Pará (TJD-PA).
} 
ABSTRACT: In the present essay, we intend to analyze Robert Alexy's concept of what constitutes Inclusive Non-Positivism. In describing Alexy's theory of law we intent to denounce the opacities of the relativistic discourse that it has just produced from the perspective of civil liability. In doing so, we opt for an opportune alternative to mitigate the relativism of discourses based on the Kantian assumption of autonomy from a reinvigoration of Aristotle and St. Thomas Aquinas throughout John Finnis' work. Although we disagree with some conservative conclusions of the Australian author, his analogical methodology becomes a possibility to objectivate the torts and insert the legal interest as criterion of validity to understand responsibility within the basic common goods.

KEYWORDS: Non Positivism; Civil Liability; Common Good; Robert Alexy; John Finnis. 


\section{SUMÁRIO:}

I. INTRODUÇÃO:

A PROPÓSITO DE UMA TEORIA DO DIREITO DISCURSIVA

II. A TEORIA do NÃo POSITIVISMO INCLUSIVO: FORNECENDO UM CONTEXTO PARA O ARGUMENTO DA RESPONSABILIDADE.....1324

III. OS BENS HUMANOS BÁSICOS: RAZOABILIDAdE PRÁTICA E BEM COMUM COMO EXIGÊNCIAS DO RECONHECIMENTO DA RESPONSABILIDADE

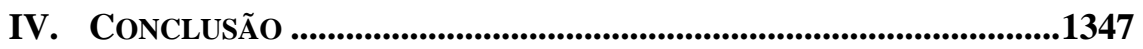

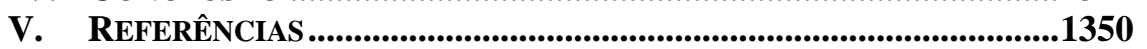

\section{TABLE OF CONTENTS:}

I. INTRODUCTION: FOR THE PURPOSE OF A DISCURSIVE LEGAL THEORY

II. THE INCLUSIVE NON-POSITIVISM THEORY: PROVIDING A CONTEXT TO THE ARGUMENT FROM RESPONSABILITY .............1324

III. THE BASIC HUMAN GOODS: PRACTICAL REASONABILITY AND COMMON GOOD AS REQUIREMENTS FOR RESPONSABILITY RECOGNITION................................................1338

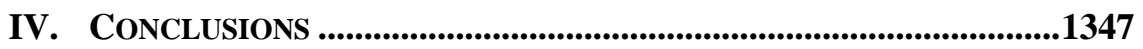

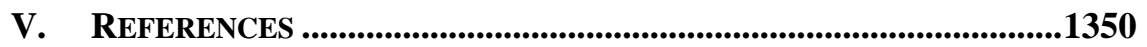




\section{INTRODUÇÃO: A PROPÓSITO DE UMA TEORIA DO DIREITO DISCURSIVA}

Escrever um ensaio comemorativo tem diversos motivos para despertar a alegria dos pesquisadores que pretendem enfrentar tal desafio. Ainda mais quando se está escrevendo em uma homenagem para figura tão ímpar na tradição jurídica paraense e brasileira. Esta celebração pode tomar como ponto de partida diversos temas e assuntos interessantes da obra e pesquisa da professora Dra. Pastora do Socorro Teixeira Leal. Enquanto Desembargadora do Tribunal Regional do Trabalho da $8^{a}$ Região, poderíamos falar de uma dimensão hermenêutica de sua obra e de suas investigações, a compreensão da aplicação do direito num determinado caso, ou, numa perspectiva argumentativa, a análise da retórica e da lógica (analítica) presentes dentro de uma justificação judicial na concessão de um direito para "a" ou para " $b$ ". Ainda neste diapasão, há uma dimensão liberal da ótica do direito sustentada pela professora em diversos julgados (porque de matriz ética kantiana), mas mantendo uma coerência natural com a influência do Jogo (como mercado), Leilão e do Seguro hipotético na estrutura da prática de uma decisão para uma democracia mais livre e igual. Neste último sentido apontamos para uma necessidade de se explorar as minúcias dessa problemática pouco estudada na obra da Professora.

As perspectivas hermenêutica, argumentativa e liberal da obra da Homenageada são muito instigantes e necessitam de uma atenção e cuidado que um breve ensaio, ou paper, não conseguiriam problematizar e se elevar à altura da exigência acadêmica que uma tal empreitada merece ao ser desenvolvida (e acreditamos que este estudo possa ser desenvolvido no futuro a partir das premissas aqui adotadas). Porém, enquanto titular da cadeira de Teoria do Direito, a professora Pastora apresenta-nos (no semestre de 2017.1) a obra de Robert Alexy a partir de sua reunião de trabalhos intitulada Teoria Discursiva do Direito. ${ }^{1}$ Dentro desta perspectiva é que pretendemos desenhar nossa singela contribuição para a acadêmica Pastora Leal. Ao apresentar a obra, a Professora Pastora se ateve na intrínseca relação entre a Teoria Discursiva e o giro linguístico presente no segundo Wittgenstein ${ }^{2} \mathrm{e}$, neste diapasão, nos apresentou ao tímido ensaio de Alexy no Capítulo II da obra supramencionada a respeito de uma teoria do direito consciente de sua necessária ligação com

${ }^{1}$ ALEXY, Robert. Teoria Discursiva do Direito. Trad. e Org. Alexandre Travessoni Gomes Trivisonno. Rio de Janeiro, RJ: Forense Universitária, 2014.

${ }^{2}$ WITTGENSTEIN, Ludwig. Investigações Filosóficas. Trad. Marcos Montagnoli. 9a ed. Petrópolis, RJ: Editora Vozes, 2014. 
a moral. ${ }^{3}$

Em outro escrito, Alexy fornece o desenho geral do seu NãoPositivismo Jurídico Inclusivo; este livro intitula-se Conceito e Validade do Direito $^{4}$, em que ele tenta explicar as falhas do discurso positivista e a necessidade de revisão de seu conteúdo a partir de três argumentos: a) o de injustiça; b) o de correção moral e; c) o dos princípios. Neste diapasão, seus escritos posteriores e anteriores se complementam a partir da leitura deste livro como sendo a "chave" para compreensão de seu pensamento (Alexy o teórico do Direito). A Teoria dos Direitos Fundamentais ${ }^{5}$ é refém de uma estrutura argumentativa fornecida na sua Teoria da Argumentação Jurídica ${ }^{6}$, e tudo isso só faz sentido se o direito não funcionar apenas com um critério "autoritativo" (legality) que lhe confira validade. Porém, Alexy se torna um escravo de suas próprias teses, que consideram a valoração individualizada dos pesos dos princípios jurídicos a partir do conhecimento das condições do caso, daí porque defende um relativismo moral no ato de aplicação do direito e, consequentemente, a impossibilidade de construção de um conceito universal para princípios de direitos fundamentais e para a própria dignidade da pessoa humana. ${ }^{7}$

Para os teóricos da Responsabilidade Civil é bastante dizer, a título de exemplificação, que as instâncias em que se pode perceber um dano (lato sensu), decorrem: a) do discurso jurídico amplamente aceito pela própria legislação; b) pelo debate travado entre os participantes do direito a fim de justificar seus julgamentos a respeito do tema; c) o reconhecimento da estrutura e do procedimento válido para resolver tais questões e; d) a ponderação dos pesos dos princípios jurídicos em jogo. Desse modo, fica evidente a possibilidade de constitucionalização do Direito Civil, a utilização dos direitos fundamentais nas relações privadas, e mais, uma dimensão axiológica no universo do Direito Civil.

${ }^{3}$ ALEXY, Robert. Teoria Discursiva do Direito. Trad. e Org. Alexandre Travessoni Gomes Trivisonno. Rio de Janeiro, RJ: Forense Universitária, 2014.

${ }^{4}$ ALEXY, Robert. Conceito e Validade do Direito. Org. Ernesto Garzón Valdés; Hartmut Kleimt; Lothar Kuhlen; Ruth Zimmerling. Trad. Gercélia Batista de Oliveira Mendes. $1^{\mathfrak{a}}$ ed. $2^{\mathrm{a}}$ tir. São Paulo, SP: WMF Martins Fontes, 2011.

${ }^{5}$ ALEXY, Robert. Teoria dos Direitos Fundamentais. Trad. Virgílio Afonso da Silva. São Paulo, SP: Malheiros, 2008.

${ }^{6}$ ALEXY, Robert. Teoria da Argumentação Jurídica: a Teoria do Discurso Racional como Teoria da Fundamentação Jurídica. Trad. Zilda Hutchinson Schild Silva. $3^{\underline{a}}$ ed. Rio de Janeiro, RJ: Forense, 2011.

7 ALEXY, Robert. Human Dignity and Proportionality Analysis. Espaço Jurídico Journal of Law, Vol. 16, 3 (Edição Especial), 2016. 
O problema é que por esta perspectiva um Juiz poderá:

a) condenar um cidadão ao pagamento de danos morais por compensação antecipada de cheque pré-datado aplicando uma decisão anterior dos Tribunais;

1. justificar sua decisão quando provocado;

2. aplicar o mesmo conteúdo de justificação a situação análoga a do cheque pré-datado (situações nas quais se presume a boa-fé objetiva das partes);

2.1. justificar os motivos da não aplicação da mesma regra para os casos análogos;

b) não condenar um cidadão por compensação antecipada de cheque pré-datado contrariando as decisões anteriores dos tribunais sendo necessário justificar o motivo da não aplicação;

1. quem não condena alguém ao pagamento de danos morais por compensação antecipada de cheque pré-datado pode vir a condenar outra pessoa pelo mesmo fato desde que justifique os motivos que o levaram a mudar de posição.

Em resumo, a teoria discursiva gera um relativismo de conteúdo, mas uma universalidade de procedimento e o conceito de dano, nesse sentido, pode objetivar seu procedimento, mas nunca sua essência. Não existe, para teoria discursiva, um dano (auto)evidente.

Dentro da práxis jurídica brasileira, não há um grande esforço para compreender o teórico do direito Alexy e a conexão necessária do seu pensamento a partir da revisão de sua obra. ${ }^{8}$ A Professora Pastora, de modo vanguardista, pretendeu nos apresentar essa dimensão do trabalho do discípulo de Habermas e nos causou, de pronto, um fascínio e profunda admiração pela coragem (virtuosa) em aceitar tal empreendimento. Ao mergulhar nesse universo, percebemos a persistente e teimosa ocorrência de um relativismo na apreensão do sentido do "ser" do direito. Isto nos causou, e continua causando, muita estranheza e insatisfação com a investigação jurídica. Será mesmo possível mitigar o relativismo dentro das teorias jurídicas? Daí surgiu a

${ }^{8}$ ALEXY, Robert. Conceito e Validade do Direito. Org. Ernesto Garzón Valdés; Hartmut Kleimt; Lothar Kuhlen; Ruth Zimmerling. Trad. Gercélia Batista de Oliveira Mendes. $1^{\underline{a}}$ ed. $2^{\underline{a}}$ tir. São Paulo, SP: WMF Martins Fontes, 2011. 
nossa problemática, em particular, a ser enfrentada neste pequeno escrito.

Um dos adversários declarados do Relativismo Jurídico é o Professor John M. Finnis, que pretende, em seu Lei Natural e Direito Natural, revigorar o jusnaturalismo através do resgate e da atualização da tradição aristotélico-tomista. ${ }^{9}$ Para Finnis, o Direito deve satisfazer às exigências de razoabilidade prática e a um determinado conjunto de bens fundamentais universais para o florescimento do ser humano. ${ }^{10}$ No seu jusnaturalismo revigorado, Finnis ataca frontalmente um erro na compreensão das ordens do conhecimento humano (natural, científica, técnica e ética). ${ }^{11}$ Advogando que Kant, por exemplo, e seus continuadores confundem a ordem ética com a ordem científica e por isso não conseguem corresponder às virtudes cardeais da Justiça e da Prudência (Iustitia e Prudentia).

Dentro da tradição em Responsabilidade Civil, isto corresponderia a uma possibilidade de transpor o paradigma kantiano da autonomia e seus reflexos na teoria discursiva e na concepção de dano. Diz-se usualmente que: "eu só sofro um dano porque sou livre para fazer ou realizar determinado ' $x$ ', quando me privam da realização de determinado ' $x$ ', ou seja, me impõem ' $y$ ', eu sofro um dano'. A ideia de dano está intimamente ligada à de liberdade e eu só sou livre porque me imputam algo, não porque posso imputar algo à alguém (conforme preceitua o jurista Kelsen ${ }^{12}$ ). Há uma influência muito grande de Kant em Kelsen e uma destas influências reside na perspectiva do direito como uma Ciência do Espírito, portanto, produto da ordem da cultura, quando o homem se apossa da natureza e a descreve ao seu modo. O que Kelsen quer dizer é simples, somente ao sofrer uma imputação eu posso pensar como se livre fosse e agir como tal.

O que Finnis está discutindo é completamente diferente e há um salto qualitativo na apreensão de uma teoria da responsabilidade baseada na

${ }^{9}$ Cf. FINNIS, John. Natural Law \& Natural Rights. $2^{\text {nd }}$ ed. Oxford: Oxford University Press, 2011; FINNIS, John. Human Rights and Common Good. Collected Essays: Volume III. Oxford: Oxford University Press, 2011; e FINNIS, John. Philosophy of Law. Collected Essays: Volume IV. Oxford: Oxford University Press, 2011.

${ }^{10}$ Cf. FINNIS, John. Natural Law \& Natural Rights. $2^{\text {nd }}$ ed. Oxford: Oxford University Press, 2011.

${ }^{11}$ Cf. FINNIS, John. Natural Law \& Natural Rights. $2^{\text {nd }}$ ed. Oxford: Oxford University Press, 2011.

${ }^{12}$ Cf. KELSEN, Hans. Teoria Pura do Direito. Trad. João Batista Machado. 8a ed. São Paulo, SP: Martins Fontes, 2009. 
"amizade" e não na liberdade. ${ }^{13}$ Aqui, estamos diante de uma alteração no argumento da responsabilidade: eu posso sofrer um dano quando o meu interesse de realizar o florescimento do meus concidadãos me é retirado, quando eu retiro a possibilidade de que meus concidadãos possam realizar seu florescimento ou quando o Estado não me fornece condições de buscar meu florescimento e de meus concidadãos. Pode-se dizer que a dimensão ética da perspectiva de dano aqui tem um peso qualitativo maior em relação à teoria dos valores e a teoria do dever. Um dano humanizado somente é possível em sua inteireza filosófica a partir desta perspectiva.

Justamente aqui é onde pretendemos alocar nossa investigação. Será mesmo possível enfrentar o relativismo na obra de Alexy a partir da alternativa fornecida por Finnis? ${ }^{14}$ Para realizar tal percurso metodológico, pretendemos realizar uma pesquisa bibliográfica de dados produzidos. Apresentaremos de modo descritivo a proposição de Alexy em seu Conceito e Validade do Direito ${ }^{15}$. Por se tratar de uma investigação da Teoria do Direito, abordaremos a primeira parte do livro, considerando que, na segunda parte, ele fornece um conceito de validade e, na terceira e última, ele resume o seu conceito a partir do confronto das informações e pesquisas realizadas em todo o livro. Nosso objetivo é analisar a tese de conexão necessária a partir da perspectiva de Alexy. ${ }^{16}$ Num segundo momento pretendemos expor de modo descritivo qual a crítica metodológica de Finnis para as teorias sociais e descritivas do direito, ao passo em que tentaremos expor a sua resposta para a questão do Direito contemporâneo. ${ }^{17}$ Nosso enfoque principal será o de expor a relação entre os bens humanos fundamentais, os requisitos de razoabilidade prática e a ideia de bem comum como o ponto central da

${ }^{13}$ Cf. FINNIS, John. Natural Law \& Natural Rights. $2^{\text {nd }}$ ed. Oxford: Oxford University Press, 2011.

${ }^{14}$ Cf. ALEXY, Robert. Conceito e Validade do Direito. Org. Ernesto Garzón Valdés; Hartmut Kleimt; Lothar Kuhlen; Ruth Zimmerling. Trad. Gercélia Batista de Oliveira Mendes. $1^{\mathrm{a}}$ ed. $2^{\mathrm{a}}$ tir. São Paulo, SP: WMF Martins Fontes, 2011; e FINNIS, John. Natural Law \& Natural Rights. $2^{\text {nd }}$ ed. Oxford: Oxford University Press, 2011. ${ }^{15}$ ALEXY, Robert. Conceito e Validade do Direito. Org. Ernesto Garzón Valdés; Hartmut Kleimt; Lothar Kuhlen; Ruth Zimmerling. Trad. Gercélia Batista de Oliveira Mendes. 1aㅡ. ed. 2a tir. São Paulo, SP: WMF Martins Fontes, 2011.

${ }^{16}$ ALEXY, Robert. Conceito e Validade do Direito. Org. Ernesto Garzón Valdés; Hartmut Kleimt; Lothar Kuhlen; Ruth Zimmerling. Trad. Gercélia Batista de Oliveira Mendes. $1^{\underline{a}}$ ed. $2^{\underline{a}}$ tir. São Paulo, SP: WMF Martins Fontes, 2011.

${ }_{17}$ FINNIS, John. Natural Law \& Natural Rights. $2^{\text {nd }}$ ed. Oxford: Oxford University Press, 2011. 
teoria finniesiana. Somente após esta análise é que pretendemos confrontar os dados coletados e apontar as diferenças e semelhanças entre os dois autores, os pontos mais relevantes de discordância entre eles e tentar responder à pergunta sobre se Finnis, ou melhor, a ideia de "bem comum" pode realmente ser uma alternativa para o problema do relativismo dentro do direito.

\section{A TeORIA do NÃo Positivismo InCLUSIVO: FORNECENDO UM CONTEXTO PARA O ARGUMENTO DA RESPONSABILIDADE}

O ponto de partida do livro Conceito e Validade do Direito ${ }^{18}$ é a dialogicidade e a apresentação superficial da tese dos positivistas e dos não positivistas com o objetivo precípuo de apontar os problemas do positivismo. Enquanto os primeiros sustentam a tese da separabilidade (a ideia de que o direito é totalmente separado da moral), os segundos argumentam pela tese da vinculação (na qual estariam presentes aspectos de elementos morais). A questão, em si, é o fato de que, quer seja positivista ou não positivista, existe um link entre as duas correntes pois reconhecem dois elementos de definição, que são: "a legalidade conforme o ordenamento ou dotada de autoridade e o da eficácia social".${ }^{19}$ Discutir essa controvérsia é discutir, em essência, o que é o direito e isso possui um aspecto prático, na medida em que essas respostas podem ser facilmente encontradas nas Cortes Constitucionais. É quase como se necessitássemos de um narrador da história do direito e (pelo menos para o Brasil) o Supremo Tribunal Federal (para a realidade alemã, Alexy se refere ao Tribunal Constitucional) seria incumbido de realizar tal tarefa. Alexy chega então a dois elementos que apontam para a crise do paradigma positivista que são descritos como: a) a injustiça legal; e b) a formação do Direito. ${ }^{20}$

${ }^{18}$ ALEXY, Robert. Conceito e Validade do Direito. Org. Ernesto Garzón Valdés; Hartmut Kleimt; Lothar Kuhlen; Ruth Zimmerling. Trad. Gercélia Batista de Oliveira Mendes. $1^{\underline{a}}$ ed. 2aㅡ. tir. São Paulo, SP: WMF Martins Fontes, 2011.

${ }^{19}$ ALEXY, Robert. Conceito e Validade do Direito. Org. Ernesto Garzón Valdés; Hartmut Kleimt; Lothar Kuhlen; Ruth Zimmerling. Trad. Gercélia Batista de Oliveira Mendes. $1^{\underline{a}}$ ed. $2^{\underline{a}}$ tir. São Paulo, SP: WMF Martins Fontes, 2011, p. 4.

${ }^{20}$ ALEXY, Robert. Conceito e Validade do Direito. Org. Ernesto Garzón Valdés; Hartmut Kleimt; Lothar Kuhlen; Ruth Zimmerling. Trad. Gercélia Batista de Oliveira Mendes. $1^{\underline{a}}$ ed. $2^{\underline{a}}$ tir. São Paulo, SP: WMF Martins Fontes, 2011, p. 6-12. 
Para o primeiro elemento (injustiça legal) ele descreve uma jurisprudência alemã (que ele vem a chamar de "aquela sobre a cidadania", ou, Staatsangehörigkeitbeschlu $\beta^{21}$ ) que versa sobre a aplicação da Lei de Cidadania do Reich, de 25 de novembro de 1941, a qual preceituava perder a nacionalidade alemã os Judeus emigrados. Nesta seara, um advogado judeu que vivia na Alemanha resolve emigrar para Amsterdã antes de iniciar a guerra. Tendo sido tomado por morto por muitos, ele acaba sendo deportado de Amsterdã para a Alemanha em 1942, instaurando o debate sobre se é constitucional, ou não, o reconhecimento da perda da sua nacionalidade. $O$ Tribunal Constitucional reconhece que uma lei pode ser validada por um determinado ordenamento, mas, ainda sim, ser uma lei injusta. Este fato é tão latente que os efeitos que são atribuídos a um tal reconhecimento são os de nulidade plena, por conta do argumento prático de que elas não possuiriam nenhum elemento vinculatório capaz de obrigar/convencer a sociedade a agir desta ou daquela forma.

Para o segundo elemento (formação do Direito), ele descreve outra jurisprudência (que ele vem a chamar de aquela sobre a formação, ou, Rechtfortblidungsbeschlu ${ }^{22}$ ) que versa, de modo bem geral, a respeito das decisões contra legem, aquelas nas quais o direito se formaria a partir da decisão judicial em contrário ao enunciado de uma lei. Para tanto, ele se apropria de uma regra do Código Civil alemão que estipula somente ser possível indenização em dinheiro para os casos previamente estipulados no próprio código ( $\$ 255$ do Bürgerliches Gesetzbuch). O que ocorre, na Alemanha, é que uma determinada revista semanal publica uma entrevista fictícia que teria sido feita com a ex-mulher do último xá do Irã, princesa Soraya..$^{23}$ Ao se debruçar sobre o caso, o Tribunal Constitucional entendeu ser cabível a indenização apesar de não haver estipulação prévia do fato no Código Civil, contrariando, desse modo, o disposto na legislação em vigor. Em conclusão, argumenta ele que "quem identifica o direito como lei escrita, ou seja, quem defende a tese do positivismo legal deve afirmar que, nos casos duvidosos, a decisão é determinada por

${ }^{21}$ ALEXY, Robert. Conceito e Validade do Direito. Org. Ernesto Garzón Valdés; Hartmut Kleimt; Lothar Kuhlen; Ruth Zimmerling. Trad. Gercélia Batista de Oliveira Mendes. $1^{\underline{a}}$ ed. $2^{\underline{a}}$ tir. São Paulo, SP: WMF Martins Fontes, 2011, p. 6.

${ }^{22}$ ALEXY, Robert. Conceito e Validade do Direito. Org. Ernesto Garzón Valdés; Hartmut Kleimt; Lothar Kuhlen; Ruth Zimmerling. Trad. Gercélia Batista de Oliveira Mendes. $1^{\underline{a}}$ ed. $2^{\underline{a}}$ tir. São Paulo, SP: WMF Martins Fontes, 2011, p. 9.

${ }^{23}$ ALEXY, Robert. Conceito e Validade do Direito. Org. Ernesto Garzón Valdés; Hartmut Kleimt; Lothar Kuhlen; Ruth Zimmerling. Trad. Gercélia Batista de Oliveira Mendes. $1^{\underline{a}}$ ed. $2^{\underline{a}}$ tir. São Paulo, SP: WMF Martins Fontes, 2011, p. 9. 
fatores extrajurídicos" e, de outra sorte, quem sustenta uma visão não positivista "como não identifica com a lei, para ele, a decisão também pode ser determinada pelo direito, se a lei não a estipular de modo coercitivo" ${ }^{24}$

Portanto, para que haja um refinamento sobre o argumento do positivismo, é necessário, antes de tudo, que sejam elencados os principais elementos do direito. Alexy os divide em três categorias, a saber: a) legalidade conforme o ordenamento; b) eficácia social; e c) correção material. ${ }^{25}$ Importante observar que a utilização de uns em detrimento de outros, ou a sobreposição de um por outro, pode levar a " $n$ " conceitos diferentes de direito. Um exemplo disso é que a utilização do elemento " $c$ " abandonando " $a$ " e "b" é uma descrição jusnaturalista. De outra sorte, utilizar " $a$ " $e$ " $b$ " abandonando " $c$ " torna-se uma descrição positivista. Dando primazia à questão da eficácia, pode-se chegar à concepções sociológicas e realistas do direito que possuem como condições de justificativa teórica: a) um aspecto externo, que "consiste na regularidade de sua [norma] observância e/ou sanção de sua não observância" 26; ou b) um aspecto interno, que "consiste na motivação independentemente de como ela é formada - de sua observância e/ou aplicação" 27 . Estes dois são os chamados conceitos de direitos orientados primariamente pela eficácia (descritos a partir do seu aspecto externo e interno).

Se se levar em conta que é possível sobrepor o elemento "a" aos outros elementos, poderíamos falar de um conceito de direito diverso do explicado no parágrafo anterior, mas, igualmente, interessante. Seriam os conceitos de direito orientados primariamente para normatização, que são divididos a partir da teoria analítica de John Austin, pela teoria

${ }^{24}$ ALEXY, Robert. Conceito e Validade do Direito. Org. Ernesto Garzón Valdés; Hartmut Kleimt; Lothar Kuhlen; Ruth Zimmerling. Trad. Gercélia Batista de Oliveira Mendes. $1^{\mathfrak{a}}$ ed. $2^{\underline{a}}$ tir. São Paulo, SP: WMF Martins Fontes, 2011, p. 12.

${ }^{25}$ ALEXY, Robert. Conceito e Validade do Direito. Org. Ernesto Garzón Valdés; Hartmut Kleimt; Lothar Kuhlen; Ruth Zimmerling. Trad. Gercélia Batista de Oliveira Mendes. $1^{\underline{a}}$ ed. $2^{\underline{a}}$ tir. São Paulo, SP: WMF Martins Fontes, 2011, p. 15-16.

${ }^{26}$ ALEXY, Robert. Conceito e Validade do Direito. Org. Ernesto Garzón Valdés; Hartmut Kleimt; Lothar Kuhlen; Ruth Zimmerling. Trad. Gercélia Batista de Oliveira Mendes. $1^{\underline{a}}$ ed. $2^{\underline{a}}$ tir. São Paulo, SP: WMF Martins Fontes, 2011, p. 18.

${ }^{27}$ ALEXY, Robert. Conceito e Validade do Direito. Org. Ernesto Garzón Valdés; Hartmut Kleimt; Lothar Kuhlen; Ruth Zimmerling. Trad. Gercélia Batista de Oliveira Mendes. $1^{\underline{a}}$ ed. $2^{2}$ tir. São Paulo, SP: WMF Martins Fontes, 2011, p. 19. 
normativista de Hans Kelsen, e pelo softpositivism de Herbert Hart. ${ }^{28}$ De toda forma, o ponto de apoio em todas estas explicações é a opção pela utilização da tese de separação e é isso que as jurisprudências citadas alhures vêm mostrar: que a tese de separação (se não é inteiramente equivocada) não é (também) inteiramente evidente..$^{29}$ Por isso decorre a necessidade de se debruçar de modo mais profundo acerca dos argumentos fornecidos pela tese da separação e a tese da vinculação como crítica ao modelo positivista. Dois argumentos surgem para a explicação de tal contenda: a) o argumento analítico, e; b) o argumento normativo. Os positivistas podem explicar o direito através da tese da separação sustentando que "não existe nenhuma conexão conceitualmente necessária entre direito e moral" ${ }^{30}$, da mesma forma, o não positivista poderia discordar e, ainda que abdicasse em defender a posição de uma conexão conceitual necessária entre direito e moral, poderia recorrer a um argumento normativo para poder derrotar um argumento positivista. Para a compreensão de um argumento normativo torna-se necessário o recurso ao termo "necessidade normativa", advertindo Alexy:

A necessidade normativa deve ser estritamente distinguida da necessidade conceitual. $\mathrm{O}$ fato de algo ser normativamente necessário quer dizer simplesmente que é ordenado. Pode-se contestar a validade de uma ordem sem incorrer numa contradição, mas não a existência de uma necessidade conceitual. Desse modo, fica claro que a necessidade normativa é apenas uma necessidade em sentido amplo. ${ }^{31}$

Nesse contexto, Alexy explica um quadro conceitual para a discussão

${ }^{28}$ ALEXY, Robert. Conceito e Validade do Direito. Org. Ernesto Garzón Valdés; Hartmut Kleimt; Lothar Kuhlen; Ruth Zimmerling. Trad. Gercélia Batista de Oliveira Mendes. $1^{\underline{a}}$ ed. $2^{\underline{a}}$ tir. São Paulo, SP: WMF Martins Fontes, 2011, p. 20-23.

${ }^{29}$ ALEXY, Robert. Conceito e Validade do Direito. Org. Ernesto Garzón Valdés; Hartmut Kleimt; Lothar Kuhlen; Ruth Zimmerling. Trad. Gercélia Batista de Oliveira Mendes. 1aㅡ ed. ${ }^{a}$ tir. São Paulo, SP: WMF Martins Fontes, 2011, p. 24.

${ }^{30}$ ALEXY, Robert. Conceito e Validade do Direito. Org. Ernesto Garzón Valdés; Hartmut Kleimt; Lothar Kuhlen; Ruth Zimmerling. Trad. Gercélia Batista de Oliveira Mendes. $1^{\underline{a}}$ ed. $2^{2}$ tir. São Paulo, SP: WMF Martins Fontes, 2011, p. 25.

${ }^{31}$ ALEXY, Robert. Conceito e Validade do Direito. Org. Ernesto Garzón Valdés; Hartmut Kleimt; Lothar Kuhlen; Ruth Zimmerling. Trad. Gercélia Batista de Oliveira Mendes. $1^{\underline{a}}$ ed. $2^{\underline{a}}$ tir. São Paulo, SP: WMF Martins Fontes, 2011, p. 26. 
das duas teses a partir de cinco premissas: a) conceitos de Direito isentos e não isentos de validade; b) sistemas jurídicos como sistemas normativos e como de procedimentos; c) a perspectiva do observador e a do participante; d) conexões classificadoras e qualificadoras; e, e) combinações. ${ }^{32}$ No que tange ao tópico "a", ao consagrar a ideia de que um determinado conceito de Direito pode prescindir de conexão com a validade da norma (ou, não) apoia sua argumentação na necessidade de o positivismo ser descrito como um conceito de Direito não isento de validade. $O$ faz pelo fato de acreditar que ao se incluir a questão sobre a validade dentro do conceito de Direito se está optando pela bandeira de uma não conexão conceitualmente necessária entre direito e moral. Em continuidade, a questão sobre o sistema de procedimentos ou normativo é colocada de modo a entender que:

\begin{abstract}
Como sistema de procedimentos, o sistema jurídico é um sistema de ações baseadas em regras e direcionadas por regras, por meio das quais as normas são promulgadas, fundamentadas, interpretadas, aplicadas e impostas. Como sistema normativo, o sistema jurídico é um sistema de resultados ou de produtos de procedimentos que, de alguma maneira, criam normas. Poder-seia dizer que aquele que considera o sistema jurídico um sistema normativo refere-se a seu aspecto externo. Em contrapartida, trata-se do aspecto interno quando o sistema jurídico é considerado um sistema de procedimentos. ${ }^{33}$
\end{abstract}

A visão do ponto de vista interno e externo é refinada pela perspectiva do interprete e do observador. Enquanto, na primeira, está-se a se referir à perspectiva de alguém que participa de uma argumentação sobre o conteúdo essencial a respeito do que nele está contido (seja um juiz, advogado, ou cidadão), na segunda, está-se diante de uma pessoa que não se questiona a respeito do fato de uma decisão/interpretação ser, possivelmente, correta ou errada; quer o segundo apenas descobrir como se chega àquela determinada decisão/interpretação. A respeito das conexões classificadoras e qualificadoras, a descrição é bem objetiva:

${ }^{32}$ Cf. ALEXY, Robert. Conceito e Validade do Direito. Org. Ernesto Garzón Valdés; Hartmut Kleimt; Lothar Kuhlen; Ruth Zimmerling. Trad. Gercélia Batista de Oliveira Mendes. $1^{\underline{a}}$ ed. $2^{\underline{a}}$ tir. São Paulo, SP: WMF Martins Fontes, 2011.

${ }^{33}$ ALEXY, Robert. Conceito e Validade do Direito. Org. Ernesto Garzón Valdés; Hartmut Kleimt; Lothar Kuhlen; Ruth Zimmerling. Trad. Gercélia Batista de Oliveira Mendes. $1^{\underline{a}}$ ed. $2^{\underline{a}}$ tir. São Paulo, SP: WMF Martins Fontes, 2011, p. 29-30. 
"trata-se de uma conexão classificadora quando se afirma que normas ou sistemas normativos que não satisfazem determinado critério moral, por razões conceituais ou normativas, não são normas jurídicas nem sistemas jurídicos". ${ }^{34}$ De outra sorte, o jurista alemão trabalha as conexões qualificadoras como sendo afirmações de "que normas ou sistemas normativos que não satisfazem um critério moral, embora possam ser normas jurídicas ou sistemas jurídicos, são, por razões conceituais ou normativas, normas jurídicas ou sistemas jurídicos defeituosos" ${ }^{35}$

Observando este quadro conceitual fornecido, trinta e duas combinações seriam possíveis a partir das quatro primeiras premissas que justificariam ou negariam a tese da separabilidade. Para Alexy, sessenta e quatro combinações seriam possíveis e a grande controvérsia sobre o direito positivo reside no fato de que muitos dos juristas desconhecem as raízes epistêmicas dessas sessenta e quatro combinações, não muito raro esses juristas "não reconhecem que a tese que defendem é totalmente diferente da que atacam" ${ }^{36}$ Há, igualmente, uma indicação pretérita para mitigar a complexidade dessas possíveis combinações: a perspectiva do participante e a perspectiva do observador. Justamente tal perspectiva é a que se torna guia para a continuação do trabalho. Bem, se se considerar que a qualidade jurídica é atribuída para aquelas situações em que se consegue chegar a justiça, está-se diante da uma perspectiva de uma tese da vinculação relacionada a uma conexão classificadora. ${ }^{37} \mathrm{O}$ argumento da injustiça, perversão, ou totalitarismo começa a ser tratado como uma forma de se medir a qualidade jurídica pela sua vinculação com a moral. O problema a ser enfrentado parte da questão de se a desqualificação do direito pela tese da injustiça seria uma questão de

${ }^{34}$ ALEXY, Robert. Conceito e Validade do Direito. Org. Ernesto Garzón Valdés; Hartmut Kleimt; Lothar Kuhlen; Ruth Zimmerling. Trad. Gercélia Batista de Oliveira Mendes. $1^{\underline{a}}$ ed. $2^{\underline{a}}$ tir. São Paulo, SP: WMF Martins Fontes, 2011, p. 31.

${ }^{35}$ ALEXY, Robert. Conceito e Validade do Direito. Org. Ernesto Garzón Valdés; Hartmut Kleimt; Lothar Kuhlen; Ruth Zimmerling. Trad. Gercélia Batista de Oliveira Mendes. $1^{a}$ ed. $2^{a}$ tir. São Paulo, SP: WMF Martins Fontes, 2011, p. 31.

${ }^{36}$ ALEXY, Robert. Conceito e Validade do Direito. Org. Ernesto Garzón Valdés; Hartmut Kleimt; Lothar Kuhlen; Ruth Zimmerling. Trad. Gercélia Batista de Oliveira Mendes. $1^{\underline{a}}$ ed. $2^{\underline{a}}$ tir. São Paulo, SP: WMF Martins Fontes, 2011, p. 32.

${ }^{37}$ ALEXY, Robert. Conceito e Validade do Direito. Org. Ernesto Garzón Valdés; Hartmut Kleimt; Lothar Kuhlen; Ruth Zimmerling. Trad. Gercélia Batista de Oliveira Mendes. $1^{\underline{a}}$ ed. $2^{\underline{a}}$ tir. São Paulo, SP: WMF Martins Fontes, 2011, p. 33. 
normas individuais ou do sistema como um todo. ${ }^{38}$

Utilizando uma premissa da Gustav Radbruch, Alexy parte de trecho da obra no qual se sustenta um conflito entre justiça e segurança jurídica. ${ }^{39}$ A partir desta concepção é fornecida uma alternativa para resolução: a) o direito positivo tem prioridade; e b) quando houver contradição entre lei positiva e justiça, ele deve ceder lugar à justiça. ${ }^{40}$ Ainda neste sentido, aponta o autor que tal prioridade deve ser interpretada a partir de uma integração dessa lei individual com seu estatuto (sistema, ou ordenamento), fato este que suportaria a alegação de que, mesmo que seu conteúdo seja injusto e não atenda a uma finalidade, o direito positivo (lei positiva) teria prioridade sobre a justiça. Somente quando houvesse um grande abismo entre a lei positiva (direito incorreto) e a justiça, o direito positivo deveria ceder lugar à justiça. A partir dessa constatação, é a posição do observador que começa a ser colocada em xeque. Seria mesmo aceitável, do ponto de vista de um observador, sustentar o argumento da injustiça?

Para Alexy, a descrição de direito por um observador diz respeito à reunião de narrativas das decisões dos tribunais no ato de aplicar o direito vigente num determinado ordenamento. ${ }^{41}$ Por isso, acredita ele que a visão do observador é uma visão neutra em relação à moral pois fica claro que "uma inclusão classificadora de elementos morais no conceito de direito que se refira a normas individuais não apenas é conceitualmente desnecessária, como também conceitualmente impossível". ${ }^{42}$ Em conclusão, a perspectiva do observador, que exige uma neutralidade moral em relação ao objeto, é um argumento que corrobora a tese da

${ }^{38}$ ALEXY, Robert. Conceito e Validade do Direito. Org. Ernesto Garzón Valdés; Hartmut Kleimt; Lothar Kuhlen; Ruth Zimmerling. Trad. Gercélia Batista de Oliveira Mendes. $1^{\underline{a}}$ ed. $2^{\underline{a}}$ tir. São Paulo, SP: WMF Martins Fontes, 2011, p. 34.

${ }^{99}$ Cf. ALEXY, Robert. Conceito e Validade do Direito. Org. Ernesto Garzón Valdés; Hartmut Kleimt; Lothar Kuhlen; Ruth Zimmerling. Trad. Gercélia Batista de Oliveira Mendes. $1^{\underline{a}}$ ed. $2^{\underline{a}}$ tir. São Paulo, SP: WMF Martins Fontes, 2011.

${ }^{40}$ ALEXY, Robert. Conceito e Validade do Direito. Org. Ernesto Garzón Valdés; Hartmut Kleimt; Lothar Kuhlen; Ruth Zimmerling. Trad. Gercélia Batista de Oliveira Mendes. $1^{\underline{a}}$ ed. $2^{\underline{a}}$ tir. São Paulo, SP: WMF Martins Fontes, 2011, p. 34.

${ }^{41}$ Cf. ALEXY, Robert. Conceito e Validade do Direito. Org. Ernesto Garzón Valdés; Hartmut Kleimt; Lothar Kuhlen; Ruth Zimmerling. Trad. Gercélia Batista de Oliveira Mendes. $1^{\underline{a}}$ ed. $2^{\underline{a}}$ tir. São Paulo, SP: WMF Martins Fontes, 2011.

${ }^{42}$ ALEXY, Robert. Conceito e Validade do Direito. Org. Ernesto Garzón Valdés; Hartmut Kleimt; Lothar Kuhlen; Ruth Zimmerling. Trad. Gercélia Batista de Oliveira Mendes. $1^{\underline{a}}$ ed. $2^{\underline{a}}$ tir. São Paulo, SP: WMF Martins Fontes, 2011, p. 36. 
separabilidade. Tudo é uma questão de perspectiva e focalização central de pontos diferentes em torno de um único ponto: o reconhecimento de um dano é justo para o país " $\mathrm{A}$ ", de acordo com suas regras internas, e injusto para o país "B" de acordo com suas regras internas. Alexy abandona completamente tal tese na medida em que sustenta que "o que é válido para uma norma individual não se aplica necessariamente a um sistema jurídico como um todo" 43 e, neste particular, portanto, o ponto de vista do argumento da injustiça na fórmula Radbruch não pode ser aceito.

Insta, portanto, argumentar que uma tese que proponha uma conexão classificadora da relação entre direito e moral somente possa fazer sentido a partir da perspectiva do participante dentro de uma análise dos sistemas jurídicos (como antagonismo da avaliação pelas normas individuais).$^{44}$ Ele opera uma distinção de dois tipos de exigências morais e elas se encontram em uma relação necessária como sistema jurídico, são chamadas de: a) distinções formais e; b) distinções materiais. Como exemplo de "a" ele cita a proposta teórica de Lon Fuller, conceituada por Alexy como uma "teoria que sustenta uma relação necessária entre critérios morais formais e o sistema jurídico (...) (internal morality of law)" ${ }^{45}$ Pautado em determinados princípios que decorrem da natureza específica do sistema jurídico (como legality, generality of law, promulgation e retroactive laws), Fuller inclui internamente aspectos de moralidade no sistema jurídico. Outra perspectiva, esta, porém, material, é atribuída a Otfreid Höffe quando vincula os sistemas normativos a uma necessária satisfação de critérios fundamentais da justiça para que possam ser reconhecidos qualitativamente como jurídicos..$^{46}$

Para compreensão desee quadro que se desenha, Alexy propõe que se

${ }^{43}$ ALEXY, Robert. Conceito e Validade do Direito. Org. Ernesto Garzón Valdés; Hartmut Kleimt; Lothar Kuhlen; Ruth Zimmerling. Trad. Gercélia Batista de Oliveira Mendes. $1^{\mathfrak{a}}$ ed. $2^{\underline{a}}$ tir. São Paulo, SP: WMF Martins Fontes, 2011, p. 37.

${ }^{44}$ ALEXY, Robert. Conceito e Validade do Direito. Org. Ernesto Garzón Valdés; Hartmut Kleimt; Lothar Kuhlen; Ruth Zimmerling. Trad. Gercélia Batista de Oliveira Mendes. $1^{\mathfrak{a}}$ ed. $2^{a}$ tir. São Paulo, SP: WMF Martins Fontes, 2011, p. 37-38.

45 "Entre esses critérios, Fuller inclui os princípios do Estado de direito (legality), como o da generalidade da lei (generality of law), o da promulgação (promulgation) e o da proibição da retroatividade (retroactive laws)". ALEXY, Robert. Conceito e Validade do Direito. Org. Ernesto Garzón Valdés; Hartmut Kleimt; Lothar Kuhlen; Ruth Zimmerling. Trad. Gercélia Batista de Oliveira Mendes. 1aㅡ ed. $2^{a}$ tir. São Paulo, SP: WMF Martins Fontes, 2011, p. 38.

${ }^{46}$ ALEXY, Robert. Conceito e Validade do Direito. Org. Ernesto Garzón Valdés; Hartmut Kleimt; Lothar Kuhlen; Ruth Zimmerling. Trad. Gercélia Batista de Oliveira Mendes. $1^{\underline{a}}$ ed. $2^{2}$ tir. São Paulo, SP: WMF Martins Fontes, 2011, p. 38. 
faça uma distinção entre conexões fáticas e conexões conceituais entre direito e moral. ${ }^{47}$ Ele utiliza o exemplo de dois tipos de ordenamentos sociais que não são sistemas jurídicos por três razões puramente conceituais: a) ordenamento absurdo; b) ordenamento predatório ou rapaces e; c) ordenamento de dominadores. O primeiro é descrito da seguinte maneira: "Tem-se um ordenamento absurdo quando um grupo de indivíduos é dominado de tal modo que é impossível tanto reconhecer finalidades consistentes do(s) dominador(es) quanto perseguir de forma duradoura a finalidade dos dominados" ${ }^{48} \mathrm{O}$ exemplo utilizado é o de uma anarquia baseada no medo e na violência, como no caso de um grupo de bandoleiros armados que domina um grupo de pessoas pautados numa única regra: a de liberdade para o exercício da violência. Nesse caso, qualquer regra emanada por um dos bandoleiros (regra individual) deve ser seguida pelo dominado e qualquer um dos bandoleiros deve considerar a liberdade para o exercício da violência (regra geral). ${ }^{49}$ Daí a conclusão de que, nesse tipo de organização social, as regras não podem remeter a um sistema jurídico.

À medida que os bandoleiros se organizam, criam hierarquia, desenvolvem regras e caminham para fora de uma anarquia (introdução da proibição de violência, de um sistema e regra para manutenção do domínio, etc.), o sistema absurdo se transmuta num sistema predatório ou rapace..$^{50}$ Para deixar mais clara sua argumentação, Alexy sustenta a hipótese de o grupo de bandoleiros obter a maior parte das suas rendas pela comercialização dos órgãos dos dominados. Portanto, devem se criar regras capazes de manter certo grau de conservação da saúde e bem estar

${ }^{47}$ ALEXY, Robert. Conceito e Validade do Direito. Org. Ernesto Garzón Valdés; Hartmut Kleimt; Lothar Kuhlen; Ruth Zimmerling. Trad. Gercélia Batista de Oliveira Mendes. $1^{\mathrm{a}}$ ed. $2^{\mathrm{a}}$ tir. São Paulo, SP: WMF Martins Fontes, 2011, p. 38-39.

${ }^{48}$ ALEXY, Robert. Conceito e Validade do Direito. Org. Ernesto Garzón Valdés; Hartmut Kleimt; Lothar Kuhlen; Ruth Zimmerling. Trad. Gercélia Batista de Oliveira Mendes. 1aㅡ ed. ${ }^{a}$ tir. São Paulo, SP: WMF Martins Fontes, 2011, p. 39.

${ }^{49}$ ALEXY, Robert. Conceito e Validade do Direito. Org. Ernesto Garzón Valdés; Hartmut Kleimt; Lothar Kuhlen; Ruth Zimmerling. Trad. Gercélia Batista de Oliveira Mendes. $1^{\underline{a}}$ ed. $2^{\underline{a}}$ tir. São Paulo, SP: WMF Martins Fontes, 2011, p. 39.

${ }^{50}$ ALEXY, Robert. Conceito e Validade do Direito. Org. Ernesto Garzón Valdés; Hartmut Kleimt; Lothar Kuhlen; Ruth Zimmerling. Trad. Gercélia Batista de Oliveira Mendes. $1^{\underline{a}}$ ed. $2^{2}$ tir. São Paulo, SP: WMF Martins Fontes, 2011, p. 40. 
dos dominados para que estes órgãos possam ser comercializados. ${ }^{51}$ Isso acusa que, apesar de existirem regras individuais, o sistema como um todo não pode ser considerado como jurídico por razões conceituais. Numa terceira perspectiva, o ordenamento de dominadores pode ser descrito como aquele no qual os bandidos reconhecem a impraticabilidade de um sistema predatório e se transformam em dominadores através de um processo de legitimação. ${ }^{52}$ Nesse sentido, o objetivo dos dominadores continua sendo o de se manter na relação como dominadores, mas agora buscam atender a interesses convergentes aos dominados (proibição de homicídio para garantia da produtividade). ${ }^{53}$

Muito embora o terceiro exemplo seja amplamente reconhecido como injusto, ele pode ser considerado um sistema jurídico. $\mathrm{O}$ fato importante, assim, é delimitar com precisão a diferença entre o sistema de dominadores e o dos bandidos, porquanto Alexy expressamente acusa: a pretensão à correção. ${ }^{54}$ Argumenta ele que:

a pretensão à correção é um elemento necessário do conceito de direito (...) Essa tese será designada como "argumento de correção" (...) há que se constatar que sistemas normativos que não formulam explícita nem implicitamente uma pretensão à correção não são sistemas jurídicos. Todo sistema jurídico implica uma pretensão à correção. ${ }^{55}$

$\mathrm{Na}$ prática, essa diferença não implica em grandes questões. $\mathrm{O}$

${ }^{51}$ ALEXY, Robert. Conceito e Validade do Direito. Org. Ernesto Garzón Valdés; Hartmut Kleimt; Lothar Kuhlen; Ruth Zimmerling. Trad. Gercélia Batista de Oliveira Mendes. 1aㅡ ed. $2^{a}$ tir. São Paulo, SP: WMF Martins Fontes, 2011, p. 40.

${ }^{52}$ ALEXY, Robert. Conceito e Validade do Direito. Org. Ernesto Garzón Valdés; Hartmut Kleimt; Lothar Kuhlen; Ruth Zimmerling. Trad. Gercélia Batista de Oliveira Mendes. $1^{\underline{a}}$ ed. $2^{\underline{a}}$ tir. São Paulo, SP: WMF Martins Fontes, 2011, p. 41.

${ }^{53}$ ALEXY, Robert. Conceito e Validade do Direito. Org. Ernesto Garzón Valdés; Hartmut Kleimt; Lothar Kuhlen; Ruth Zimmerling. Trad. Gercélia Batista de Oliveira Mendes. $1^{\underline{a}}$ ed. $2^{\underline{a}}$ tir. São Paulo, SP: WMF Martins Fontes, 2011, p. 41.

${ }^{54}$ ALEXY, Robert. Conceito e Validade do Direito. Org. Ernesto Garzón Valdés; Hartmut Kleimt; Lothar Kuhlen; Ruth Zimmerling. Trad. Gercélia Batista de Oliveira Mendes. $1^{\underline{a}}$ ed. $2^{\underline{a}}$ tir. São Paulo, SP: WMF Martins Fontes, 2011, p. 41.

${ }^{55}$ ALEXY, Robert. Conceito e Validade do Direito. Org. Ernesto Garzón Valdés; Hartmut Kleimt; Lothar Kuhlen; Ruth Zimmerling. Trad. Gercélia Batista de Oliveira Mendes. $1^{\underline{a}}$ ed. $2^{2}$ tir. São Paulo, SP: WMF Martins Fontes, 2011, p. 42. 
problema relativo à pretensão de correção do direito somente se torna transparente quando há formulação da pretensão e não há satisfação da pretensão. Ainda assim, "a pretensão à correção representa um nexo entre as duas perspectivas [observador e participante]". ${ }^{56}$ Numa perspectiva do participante, a análise do conteúdo essencial do direito perpassa por esse estágio de reconhecimento primário (pretensão à correção), mas essencialmente se conecta com os outros dois principais argumentos (o da injustiça e o dos princípios). Toda pretensão à correção é uma pretensão à correção justa. ${ }^{57} \mathrm{Na}$ hipótese de uma classe dominante pretender manter as desigualdades sociais como forma de controle de outros dentro de uma democracia através de uma modificação constitucional, todos teriam problemas em reconhecer a validade de um artigo da constituição que contivesse a seguinte expressão: "O Estado X é soberano e injusto". Ressalvados os defeitos técnicos e os defeitos convencionais, o que Alexy aponta sendo como o maior dos defeitos é o chamado conceitual, pois, no caso, a norma carece de uma pretensão à correção justa. ${ }^{58} \mathrm{O}$ argumento da injustiça começa a ser introduzido a partir de sua vinculação a normas individuais ou sistemas jurídicos por inteiro, ponderando, antes de mais nada que:

\begin{abstract}
Nessa versão, as normas individuais de um sistema jurídico perdem o caráter jurídico quando determinado limiar da injustiça ou da iniquidade é transposto. Sua variante mais conhecida é a fórmula Radbruch, cuja solidez já foi discutida e negada a partir do ponto de vista de um observador. Doravante, trata-se de saber se o argumento da injustiça, do modo como a fórmula de Radbruch o exprime, é aceitável do ponto de vista de um participante. Para tanto, ressalte-se que a fórmula de Radbruch não afirma que uma norma perde o seu caráter jurídico por ser injusta. O limiar é fixado mais acima. O caráter
\end{abstract}

${ }^{56}$ ALEXY, Robert. Conceito e Validade do Direito. Org. Ernesto Garzón Valdés; Hartmut Kleimt; Lothar Kuhlen; Ruth Zimmerling. Trad. Gercélia Batista de Oliveira Mendes. $1^{a}$ ed. $2^{a}$ tir. São Paulo, SP: WMF Martins Fontes, 2011, p. 42.

${ }^{57}$ ALEXY, Robert. Conceito e Validade do Direito. Org. Ernesto Garzón Valdés; Hartmut Kleimt; Lothar Kuhlen; Ruth Zimmerling. Trad. Gercélia Batista de Oliveira Mendes. $1^{\underline{a}}$ ed. $2^{\underline{a}}$ tir. São Paulo, SP: WMF Martins Fontes, 2011, p. 45.

${ }^{58}$ ALEXY, Robert. Conceito e Validade do Direito. Org. Ernesto Garzón Valdés; Hartmut Kleimt; Lothar Kuhlen; Ruth Zimmerling. Trad. Gercélia Batista de Oliveira Mendes. $1^{\underline{a}}$ ed. $2^{2}$ tir. São Paulo, SP: WMF Martins Fontes, 2011, p. 45. 
jurídico só há de se perder se a injustiça atingir um "grau insustentável".59

Isto se daria muito por conta da necessidade de manutenção de um mínimo para que os direitos possam ter (ou manter) sua coerência interna dentro de um sistema jurídico determinado. Basta imaginar as razões de se proteger a vida e a tratá-la como inviolável, admitindo, ao mesmo tempo e genericamente, a possibilidade de pena de morte como uma sanção contumaz na esfera penal. A moralidade, como um mínimo aceitável para a razoabilidade prática do caso, impediria que a atribuição de uma pena de morte se tornasse coloraria a inviolabilidade do direito à vida (isto se estenderia, por óbvio, à análise de indiscriminados casos, como o exemplo sobre o direito à vida: pesquisa em células-tronco; aborto do feto anencéfalo; eutanásia; entre outros). Importante frisar, novamente, que de acordo com Alexy essa argumentação somente faria sentido na perspectiva do participante..$^{60}$

A respeito do argumento dos princípios, Alexy aduz que, partindo-se da premissa de que o argumento de injustiça visa uma situação excepcional e trata do cotidiano jurídico, o argumento dos princípios está diretamente mergulhado na questão da metodologia jurídica. ${ }^{61}$ Ou seja, o direito comporta uma textura aberta (seja através da semântica do direito, seja através de sua capacidade de se aplicar indistintamente a casos genéricos e dialogar com outras ciências para resolução de casos difíceis). Em conclusão, o argumento dos princípios somente faz sentido se existir um controle de conteúdo moral tomado a partir da perspectiva do participante e voltado para análise de normas individuais. Nesse sentido, a proposta de Alexy parece fazer certo sentido como modelo geral de explicação do fenômeno jurídico. ${ }^{62}$ Porém, ao se transportar para um cenário internacional, ela peca em determinados sentidos. Aplicando-se

${ }^{59}$ ALEXY, Robert. Conceito e Validade do Direito. Org. Ernesto Garzón Valdés; Hartmut Kleimt; Lothar Kuhlen; Ruth Zimmerling. Trad. Gercélia Batista de Oliveira Mendes. $1^{\underline{a}}$ ed. $2^{2}$ tir. São Paulo, SP: WMF Martins Fontes, 2011, p. 48.

${ }^{60}$ Cf. ALEXY, Robert. Conceito e Validade do Direito. Org. Ernesto Garzón Valdés; Hartmut Kleimt; Lothar Kuhlen; Ruth Zimmerling. Trad. Gercélia Batista de Oliveira Mendes. $1^{\underline{a}}$ ed. $2^{\underline{a}}$ tir. São Paulo, SP: WMF Martins Fontes, 2011.

${ }^{61}$ ALEXY, Robert. Conceito e Validade do Direito. Org. Ernesto Garzón Valdés; Hartmut Kleimt; Lothar Kuhlen; Ruth Zimmerling. Trad. Gercélia Batista de Oliveira Mendes. $1^{\underline{a}}$ ed. $2^{2}$ tir. São Paulo, SP: WMF Martins Fontes, 2011, p. 83.

${ }^{62}$ Cf. ALEXY, Robert. Conceito e Validade do Direito. Org. Ernesto Garzón Valdés; Hartmut Kleimt; Lothar Kuhlen; Ruth Zimmerling. Trad. Gercélia Batista de Oliveira Mendes. $1^{\underline{a}}$ ed. $2^{\underline{a}}$ tir. São Paulo, SP: WMF Martins Fontes, 2011. 
tal proposta a regimes e sistemas individuais a dinâmica da análise dos casos depende das condições em que o caso se apresenta, o que gera possibilidade para certo relativismo. Assim é a perspectiva por ele abordada em recente artigo a respeito da dignidade humana e da proporcionalidade, em que ele aduz que "If the guarantee of human dignity can and should have the structure of a principle, then the relative construction is correct". 63

Para entender o que seria a dignidade humana, Alexy propõe que ela pode ser entendida a partir de uma concepção descritiva (associada à autonomia em Kant ${ }^{64}$ ) ou empírica (associada ao ponto de vista legal, mas descartado por Alexy ${ }^{65}$ ) com elementos normativos ou avaliativos. Em última ratio, por uma questão descritiva, a dignidade humana pode ser compreendida a partir de uma dupla tríade que compreende: a) inteligência; b) sentimento e; c) consciência (como autoconsciência); esta última será desdobrada em: c1) consciência cognitiva; c2) consciência volitiva e; c3) consciência normativa. ${ }^{66}$ A ideia da existência de um relativismo na obra de Alexy não seria uma conclusão precipitada, considerando-se que os paradigmas teóricos utilizam de premissas liberais kantianas, portanto, críticas à ideia de ética universalista

${ }^{63}$ ALEXY, Robert. Human Dignity and Proportionality Analysis. Espaço Jurídico Journal of Law, Vol. 16, 3 (Edição Especial), 2016, p. 88. Tradução livre: "Se a garantia da dignidade humana pode e deve ter a estrutura de princípio, então a construção relativista é correta".

64 "Autonomy is therefore the ground of the human dignity of human nature and of every rational nature". KANT, Immanuel apud ALEXY, Robert. Human Dignity and Proportionality Analysis. Espaço Jurídico Journal of Law, Vol. 16, 3 (Edição Especial), 2016, p. 89. Tradução livre: “Autonomia é, portanto, o fundamento da dignidade humana da natureza humana de toda racionalidade natural." E ele ainda completa mais adiante: "From the point of view of moral theory, Kant is right". ALEXY, Robert. Human Dignity and Proportionality Analysis. Espaço Jurídico Journal of Law, Vol. 16, 3 (Edição Especial), 2016, p. 89. Tradução livre: “Do ponto de vista de uma teoria moral, Kant está certo".

65 "From the point of view of legal theory, however, a broader empirical basis seems to be preferable, for the legal protection of human dignity is not confined to the protection of autonomy in the sense of moral legislation". ALEXY, Robert. Human Dignity and Proportionality Analysis. Espaço Jurídico Journal of Law, Vol. 16, 3 (Edição Especial), 2016, p. 89.

${ }^{66}$ ALEXY, Robert. Human Dignity and Proportionality Analysis. Espaço Jurídico Journal of Law, Vol. 16, 3 (Edição Especial), 2016, p. 89. 
tomista. ${ }^{67}$

Evidentemente, existem méritos e deméritos na proposição alexyana. Podemos enumerá-los da seguinte maneira: a) por se tratar de uma teoria que representa a tese de vinculação necessária entre direito e moral, apresenta uma superação da perspectiva tradicionalmente sustentada a partir do segundo pós-guerra (uma atualização da episteme jurídica), ao mesmo tempo, carece de uma teoria política e ética para que ela possa ter viabilidade prática; b) por se tratar de uma teoria analítica, consegue descrever o direito a partir da perspectiva do participante de modo a compreender qualitativamente os influxos da sociedade que vinculam os cidadãos a cumprir com a lei, porém, sendo uma teoria descritiva ou normativa não consegue fugir da discricionariedade de seleção de um caso central e seleção focal; c) por não ter uma filosofia política de fundo ético bem desenvolvida, o não-positivismo inclusivo poderia se amoldar de acordo com os interesses das comunidades em que ele for adotado, porém, isto causaria uma instabilidade (de extremo relativismo) na tutela de certas condições para o florescimento humano.

Em linhas gerais, são essas as críticas que podemos fazer à construção baseada na necessidade de correção moral do cidadão enquanto elemento qualificador do direito a partir da perspectiva de Alexy. ${ }^{68} \mathrm{O}$ exemplo, na prática, que podemos fornecer é a explicação de porque existem decisões jurídicas que pretendem a correção moral de uma determinada conduta que se apresentam julgando situações análogas, mas com respostas diferentes (como no caso do cheque pré-datado). Nesse sistema, seria autorizada a aplicação do direito pelo magistrado que argumenta sobre uma questão moral enquanto critério qualitativo do direito decidir por conceder determinada garantia para " $a$ " em face de " $b$ " e vice-versa. Não existe um limite objetivo e ético para a resolução desse problema dentro da teoria de Alexy. ${ }^{69}$ Por isso escolhemos, na continuação da pesquisa, um teórico que abandona a tese de separação entre direito e moral (portanto

${ }^{67}$ Cf. ALEXY, Robert. Conceito e Validade do Direito. Org. Ernesto Garzón Valdés; Hartmut Kleimt; Lothar Kuhlen; Ruth Zimmerling. Trad. Gercélia Batista de Oliveira Mendes. $1^{\underline{a}}$ ed. $2^{\underline{a}}$ tir. São Paulo, SP: WMF Martins Fontes, 2011; e ALEXY, Robert. Human Dignity and Proportionality Analysis. Espaço Jurídico Journal of Law, Vol. 16, 3 (Edição Especial), 2016.

${ }^{68}$ ALEXY, Robert. Conceito e Validade do Direito. Org. Ernesto Garzón Valdés; Hartmut Kleimt; Lothar Kuhlen; Ruth Zimmerling. Trad. Gercélia Batista de Oliveira Mendes. $1^{\mathrm{a}}$ ed. $2^{\underline{a}}$ tir. São Paulo, SP: WMF Martins Fontes, 2011.

${ }^{69}$ ALEXY, Robert. Conceito e Validade do Direito. Org. Ernesto Garzón Valdés; Hartmut Kleimt; Lothar Kuhlen; Ruth Zimmerling. Trad. Gercélia Batista de Oliveira Mendes. $1^{\underline{a}}$ ed. 2a tir. São Paulo, SP: WMF Martins Fontes, 2011. 
adotando a tese de vinculação necessária) e que, de modo sagaz, apresenta uma teoria ética em conjunto com sua crítica metodológica e sua concepção de autoridade legal: John Finnis em seu Lei natural e Direito Natural, obra que começa a ser apresentada a partir de agora. ${ }^{70}$

\section{Os BENS HUMANOS BÁSICOS: RAZOABILIDADE PRÁTICA E BEM COMUM COMO EXIGÊNCIAS DO RECONHECIMENTO DA RESPONSABILIDADE}

O ponto de partida de Finnis é o de que as teorias modernas do direito (de cunho sociológico ou analítico) pecam na descrição do direito porque acreditam, em regra, ser possível uma descrição neutra do seu objeto. ${ }^{71}$ Logo, ele argumenta que toda descrição do direito é, automaticamente, submissa a um juízo de valor prévio que inclui a necessidade de uma seleção de um caso central e um sentido focal para as propostas investigativas de qualquer objeto de estudo ${ }^{72}$, e antes disso, deve observar o direito a partir de sua prática. ${ }^{73}$ Basicamente, a crítica do primeiro capítulo do Lei Natural e Direito Natural é acusar; a) uma lacuna ontológica na compreensão das teorias jurídicas contemporâneas na medida em que elas carecem de clareza quanto aos seus próprios métodos e escolhas e; b) a necessidade de se revigorar o direito a partir da sua prática a partir da compreensão da sua dimensão ética. ${ }^{74}$

No segundo capítulo da obra, Finnis procura demonstrar exatamente a existência dessa lacuna ao dissertar sobre a visão dos positivistas modernos como uma precipitação do que vem a ser a tese do direito natural. ${ }^{75}$ Em consequência, Finnis objeta a possibilidade de validade da

\footnotetext{
${ }^{70}$ FINNIS, John. Natural Law \& Natural Rights. $2^{\text {nd }}$ ed. Oxford: Oxford University Press, 2011.

${ }^{71}$ FINNIS, John. Natural Law \& Natural Rights. $2^{\text {nd }}$ ed. Oxford: Oxford University Press, 2011, p. 4-5.

${ }^{72}$ FINNIS, John. Natural Law \& Natural Rights. $2^{\text {nd }}$ ed. Oxford: Oxford University Press, 2011, p. 8-9.

${ }^{73}$ FINNIS, John. Natural Law \& Natural Rights. $2^{\text {nd }}$ ed. Oxford: Oxford University Press, 2011, p. 5-7.

${ }^{74}$ Cf. FINNIS, John. Natural Law \& Natural Rights. $2^{\text {nd }}$ ed. Oxford: Oxford University Press, 2011.

${ }^{75}$ FINNIS, John. Natural Law \& Natural Rights. $2^{\text {nd }}$ ed. Oxford: Oxford University Press, 2011, p. 24-29.
} 
crítica positivista ao direito natural pelo simples fato de os positivistas (supostamente) não estarem falando sobre a tradição do direito natural, mas sim sobre uma imagem não fidedigna que acaba representando toda a tradição. ${ }^{76}$

Apesar de ser um debate extenso e milimetricamente calculado, além de persistirem algumas críticas para os argumentos levantados por Finnis, não é este o escopo principal da nossa pesquisa, mas sim o desenvolvimento da teoria ética de Finnis a partir da ideia de evidência de um conjunto de bens humanos básicos como um requisito para coordenação das comunidades humanas e para o florescimento (eudaimonia - felicidade) humano. ${ }^{77}$ Finnis (2011-a) parte de um pressuposto aristotélico-tomista porque acredita que a felicidade é o fim e o objetivo último da existência humana, mas ela somente pode ser alcançada verdadeiramente através da aplicação das virtudes cardeais (justiça, prudência, temperança e fortaleza), dando maior ênfase às duas primeiras.

O primeiro bem humano básico apresentado é o conhecimento humano ${ }^{78}$, e ele procura conceituar o que é "conhecimento" como um bem humano básico acabando por dividir o que se compreende como formas de conhecimento: a) técnico; b) por curiosidade. Essencialmente, o capítulo tratará do conhecimento como uma atividade humana de tentativa e erro. ${ }^{79}$ Ainda nesse sentido, sustenta ele que "Curiosity is a name for the desire or inclination or felt want that we have when, just for the sake of knowing, we want to find out about something" ${ }^{80}$ Apesar de esse sentimento não despertar uma inclinação a valores, ele é erroneamente chamado como "ter interesse em alguma coisa". ${ }^{81}$ Desse interesse no conhecimento, origina-se a busca pela verdade. Logo, conhecimento, interesse e verdade são objetivos razoáveis na análise da esfera de ação humana.

${ }^{76}$ Cf. FINNIS, John. Natural Law \& Natural Rights. 2nd $e d$. Oxford: Oxford University Press, 2011.

${ }_{77}$ Cf. FINNIS, John. Natural Law \& Natural Rights. $2^{\text {nd }}$ ed. Oxford: Oxford University Press, 2011.

${ }^{78}$ FINNIS, John. Natural Law \& Natural Rights. $2^{\text {nd }}$ ed. Oxford: Oxford University Press, 2011, p. 58-74.

${ }^{79}$ FINNIS, John. Natural Law \& Natural Rights. $2^{\text {nd }}$ ed. Oxford: Oxford University Press, 2011, p. 60.

${ }^{80}$ FINNIS, John. Natural Law \& Natural Rights. $2^{\text {nd }}$ ed. Oxford: Oxford University Press, 2011, p. 60.

${ }^{81}$ FINNIS, John. Natural Law \& Natural Rights. $2^{\text {nd }}$ ed. Oxford: Oxford University Press, 2011, p. 61. 
Mas o conhecimento, refuta Finnis, não pode ser tratado como, ou enquanto, um valor por diversos motivos. $O$ principal deles é o relativismo que pode se derivar de tal análise (se o conhecimento realmente fosse, ou derivasse de um valor subjetivo, significaria que a verdade dependeria de um ponto de vista, não persistindo uma crítica séria aos fundamentos dos paradigmas científicos). ${ }^{82}$ Igualmente, Finnis sustenta que o conhecimento é um princípio prático, informativo, uma vez que as pessoas buscam o conhecimento e evitam a ignorância pois precisam evidenciar a fonte da razão de porquê agir. ${ }^{83}$

Ainda que alguém vá de encontro com uma proposição prática que porventura outrem tome, o conhecimento é um bem humano básico e prático na medida em que é compartilhado pelos participantes do debate, não sendo, portanto, exclusivo de um dos dois. ${ }^{84}$ Disso decorre sua autoevidência enquanto uma forma de bem humano, sentenciando ele que "The good of knowledge is self-evident, obvious. It cannot be demonstrated, but equally it needs no demonstration" ${ }^{85} \mathrm{O}$ princípio da verdade não é perseguido por todos os seres humanos desde seu nascimento. Apenas quando ele se torna um problema do conhecimento, transforma-se num princípio prático, ou seja, o conhecimento é autoevidente na medida em que é pressuposto da busca pela verdade. ${ }^{86}$

Apenas a partir do quarto capítulo da obra, Finnis busca apresentar uma lista dos bens humanos considerados como básicos e condições necessárias para o florescimento humano. ${ }^{87}$ Tendo partido do conhecimento e o sedimentado enquanto um bem humano básico porque todo o homem atinge a felicidade através da busca pela verdade e pelo conhecimento de algo, a lista de Finnis vai passar a incluir: a) vida ${ }^{88}$; b)

${ }^{82}$ FINNIS, John. Natural Law \& Natural Rights. $2^{\text {nd }}$ ed. Oxford: Oxford University Press, 2011, p. 62.

${ }^{83}$ FINNIS, John. Natural Law \& Natural Rights. $2^{\text {nd }}$ ed. Oxford: Oxford University Press, 2011, p. 63.

${ }^{84}$ FINNIS, John. Natural Law \& Natural Rights. $2^{\text {nd }}$ ed. Oxford: Oxford University Press, 2011, p. 64.

${ }^{85}$ FINNIS, John. Natural Law \& Natural Rights. $2^{\text {nd }}$ ed. Oxford: Oxford University Press, 2011, p. 65.

${ }^{86}$ FINNIS, John. Natural Law \& Natural Rights. $2^{\text {nd }}$ ed. Oxford: Oxford University Press, 2011, p. 65.

${ }^{87}$ FINNIS, John. Natural Law \& Natural Rights. $2^{\text {nd }}$ ed. Oxford: Oxford University Press, 2011, p. 85.

88 "A first basic value, corresponding to the drive for self-preservation, is the value of life. The term 'life' here signifies every aspect of the vitality (vita, life) which puts a 
conhecimento $^{89}$; c) jogo ${ }^{90}$; d) experiência estética ${ }^{91}$; e) sociabilidade (amizade) ${ }^{92}$; f) razoabilidade prática93; g) religião ${ }^{94}$. Existiriam, porém, outros bens humanos básicos além desses sete fornecidos na argumentação finniseiana? Bem, para o autor australiano, a lista de bens humanos não é exaustiva, podendo existir outros bens humanos, mas eles são combinações ou formas de execução (mal sucedidas) dos bens constantes nessa lista..$^{95}$ Ainda nessa esteira, teria a vida uma hierarquia maior do que a experiência estética ou o conhecimento? A resposta é negativa. De acordo com Finnis, todos os bens são igualmente

human being in good shape for self-determination. Hence, life here includes bodily (including cerebral) health, and freedom from the pain that betokens organic malfunctioning or injury". FINNIS, John. Natural Law \& Natural Rights. $2^{\text {nd }} e d$. Oxford: Oxford University Press, 2011, p. 86.

89 "The second basic value I have already discussed: it is knowledge, considered as desirable for its own sake, not merely instrumentally". FINNIS, John. Natural Law \& Natural Rights. $2^{\text {nd }}$ ed. Oxford: Oxford University Press, 2011, p. 87.

90 "An element of play can enter into any human activity, even the drafting of enactments, but is always analytically distinguishable from its 'serious' context; and some activities, enterprises, and institutions are entirely or primarily pure play. Play, than, has and is its own value". FINNIS, John. Natural Law \& Natural Rights. $2^{\text {nd }}$ ed. Oxford: Oxford University Press, 2011, p. 87.

91 "Aesthetic experience, unlike play, need not involve an action of one's own; what is sought after and valued for its own sake may simply be the beautiful form 'outside' one, and the 'inner' experience of appreciation of its beauty". FINNIS, John. Natural Law \& Natural Rights. $2^{\text {nd }}$ ed. Oxford: Oxford University Press, 2011, p. 87-88.

92 “But friendship involves acting for the sake of one's friend's purposes, one's friend's well being. To be in a relationship of friendship with at least one other person is a fundamental form of good". FINNIS, John. Natural Law \& Natural Rights. $2^{\text {nd }} e d$. Oxford: Oxford University Press, 2011, p. 88.

93 “(...) its the basic good of being able to bring one's own intelligence to bear effectively (in practical reasoning that issues in action) on the problem of choosing one's actions and life-style and shaping one's own character". FINNIS, John. Natural Law \& Natural Rights. $2^{\text {nd }}$ ed. Oxford: Oxford University Press, 2011, p. 88-89. 94 " $(. .$.$) the notion that one of the basic human value is the establishment and$ maintenance of proper relationships between oneself (and the orders one can create and maintain) and the divine [ou, melhor, a característica transcendente do 'ser' humano]". FINNIS, John. Natural Law \& Natural Rights. $2^{\text {nd }}$ ed. Oxford: Oxford University Press, 2011, p. 89-90.

${ }_{95}$ FINNIS, John. Natural Law \& Natural Rights. $2^{\text {nd }}$ ed. Oxford: Oxford University Press, 2011, p. 89-90. 
autoevidentes enquanto bens, nenhum deles podendo ser reduzido analiticamente e instrumentalizado para perseguir objetivos rivais. ${ }^{96}$ Cada um deles pode ter uma importância maior do que a do outro, dependendo da seleção focal ou do caso central. Logo, não existe uma hierarquia objetiva entre eles. ${ }^{97}$

Apesar dessa constatação, Finnis não é cego para o fato de que, um desses bens pode vir a ser considerado (compreendido e estudado) como condição de possibilidade para a prática dos outros. ${ }^{98}$ Essa é a razoabilidade prática (practical reasonbless). ${ }^{99}$ Ela diz respeito ao que se pode chamar da teoria ética (enquanto análise do agir, ou seja, da prática) que se encontra perene na retórica de Finnis. ${ }^{100}$ Para que uma decisão possa ser tomada a partir da razoabilidade prática, Finnis elenca alguns requisitos necessários, são eles: a) plano de vida coerente ${ }^{101}$; b) não existência de preferências arbitrárias entre valores defendidos ${ }^{102}$; c) não existência de preferências arbitrárias entre pessoas ${ }^{103}$; d) desprendimento

${ }^{96}$ Cf. FINNIS, John. Natural Law \& Natural Rights. $2^{\text {nd }}$ ed. Oxford: Oxford University Press, 2011.

${ }^{97}$ FINNIS, John. Natural Law \& Natural Rights. $2^{\text {nd }}$ ed. Oxford: Oxford University Press, 2011, p. 92-93.

${ }_{98}$ Cf. FINNIS, John. Natural Law \& Natural Rights. $2^{\text {nd }}$ ed. Oxford: Oxford University Press, 2011.

${ }^{99}$ FINNIS, John. Natural Law \& Natural Rights. $2^{\text {nd }}$ ed. Oxford: Oxford University Press, 2011, p. 100-101.

${ }^{100}$ Cf. FINNIS, John. Natural Law \& Natural Rights. $2^{\text {nd }}$ ed. Oxford: Oxford University Press, 2011.

${ }^{101}$ Baseado num princípio rawlseano, Finnis acredita que devemos ter planos de vida racionais, harmônicos e com propósitos orientados a partir da assunção de compromissos efetivos (dos pais com o bem-estar dos filhos, dos cônjuges para com a manutenção da sociedade matrimonial, do professor com a busca pelo conhecimento, etc.). FINNIS, John. Natural Law \& Natural Rights. $2^{\text {nd }}$ ed. Oxford: Oxford University Press, 2011, p. 103-104.

102 “(...) there must be no leaving out of account, or arbitrary discounting or exaggeration, of any of the basic human values. Any commitment to a coherent plan of life is going to involve some degree of concentration on one or some of the basic forms of good, at the expense, temporarily or permanently, of other forms of good. But the commitment will be rational only if it is on the basis of one's assessment of one's capacities, circumstances, and even of one's tastes". FINNIS, John. Natural Law \& Natural Rights. $2^{\text {nd }}$ ed. Oxford: Oxford University Press, 2011, p. 105.

103 "My own well-being (which, as we shall see, includes a concern for the well-being of others, my friends: see VI.4; but ignore this for the moment) is reasonably the first 
e compromisso ${ }^{104}$; e) a (limitada) relevância das consequências ${ }^{105}$; f) respeito por qualquer valor básico em qualquer ação ${ }^{106} ; \mathrm{g}$ ) os requisitos

claim on my interest, concern, and effort. Why can I so regard it? Not because it is of more value than the well-being of others, simply because it is mine: intelligence and reasonableness can find no basis in the mere fact that $\mathrm{A}$ is $\mathrm{A}$ and is not $\mathrm{B}$ (that $\mathrm{I}$ am I and am not you) for evaluating his (our) well-being differentially. No: the only reason for me to prefer my well-being is that it is through my self-determined and selfrealizing participation in the basic goods that I can do what reasonableness suggests and requires, viz. favour and realize the forms of human good indicated in the first principles of practical reason". FINNIS, John. Natural Law \& Natural Rights. $2^{\text {nd }} e d$. Oxford: Oxford University Press, 2011, p. 107.

${ }^{104}$ De acordo com Finnis aqui não se está diante de apenas um requisito de razoabilidade prática, mas sim de dois e eles estão diretamente ligados à adoção de um plano de vida coerente e do estabelecimento de ordens de prioridades e de um conjunto de compromissos básicos que são assumidos por conta da adoção do plano de vida. FINNIS, John. Natural Law \& Natural Rights. $2^{\text {nd }}$ ed. Oxford: Oxford University Press, 2011, p. 109. Eles dizem respeito ao desapego/desprendimento de todos os projetos limitados e específicos que são contrários à prática do projeto de vida coerente adotado (por exemplo, se eu adoto um projeto de vida para fins de florescimento humano a partir da adoção e promoção de bem-estar de crianças carentes, devo assumir que não trabalharei numa determinada profissão específica com o mesmo rigor, por conta da necessidade especial das crianças adotadas, não podendo, desse modo, viajar por longos períodos de tempo, etc.); na mesma medida do compromisso sério em atingir esses objetivos como forma de consecução do florescimento humano. FINNIS, John. Natural Law \& Natural Rights. $2^{\text {nd }}$ ed. Oxford: Oxford University Press, 2011, p. 110.

105 "For this is the requirement that one bring about good in the world (in one's own life and the lives of others) by actions that are efficient for their (reasonable) purpose(s). One must not waste one's opportunities by using inefficient methods. One's actions should be judged by their effectiveness, by their fitness for their purpose, by their utility, their consequences..." FINNIS, John. Natural Law \& Natural Rights. $2^{\text {nd }}$ ed. Oxford: Oxford University Press, 2011, p. 111.

106 "A first formulation is that one should not choose to do any act which of itself does nothing but damage or impede a realization or participation of any one or more of the basic forms of human good. For the only 'reason' for doing such an act, other than the non-reason of some impelling desire, could be that the good consequences of the act outweigh the damage done in and through the act itself". FINNIS, John. Natural Law \& Natural Rights. $2^{\text {nd }}$ ed. Oxford: Oxford University Press, 2011, p. 118. 
do bem comum ${ }^{107}$; h) seguir sua própria consciência ${ }^{108}$ e; f) a moralidade como produto dos requisitos de razoabilidade prática ${ }^{109}$.

Esse é o grande trunfo de Finnis contra o relativismo. ${ }^{110}$ Enquanto as teorias do direito moderno que advogam a tese de separabilidade entendem que teoria do direito e ética são disciplinas apartadas uma da outra, necessitando de estudos separados, a teoria do direito natural revigorado apresenta, dentro de sua preocupação, uma teoria ética, consequentemente, uma teoria política. Esse é o esforço empreendido pelo jusfilósofo australiano que denota, não só metodologicamente, uma crítica aberta ao relativismo. Ao fornecer um pano de fundo ético para sua teoria a partir dos bens humanos básicos, Finnis está dizendo, na verdade, o que se deverá entender por direito, validade, autoridade, leis e ultimamente, leis injustas. ${ }^{111}$ Não é nosso propósito esgotar a teoria ética de Finnis a partir desse reconhecimento, mas, especificamente, demonstrar quão grande é a importância da discussão do bem comum a partir da ética aristotélico-tomista na reconfiguração da noção de

107 "Very many, perhaps even most, of our concrete moral responsibilities, obligations, and duties have their basis in the eighth requirement. We can label this the requirement of favouring and fostering the common good of one's communities. The sense and implications of this requirement are complex and manifold". FINNIS, John. Natural Law \& Natural Rights. $2^{\text {nd }}$ ed. Oxford: Oxford University Press, 2011, p. 125. 108 "It is the requirement that one should not do what one judges or thinks or 'feels'-allin-all should not be done. That is to say one must act 'in accordance with one's conscience'". FINNIS, John. Natural Law \& Natural Rights. $2^{\text {nd }}$ ed. Oxford: Oxford University Press, 2011, p. 125.

109 "Now we can see why some philosophers have located the essence of 'morality' in the reduction of harm, others in the increase of wellbeing, some in social harmony, some in universalizability of practical judgment, some in the all-round flourishing of the individual, others in the preservation of freedom and personal authenticity. Each of these has a place in rational choice of commitments, projects, and particular actions. Each, moreover, contributes to the sense, significance, and force of terms such as 'moral', '[morally] ought', and 'right'; not every one of the nine requirements has a direct role in every moral judgment, but some moral judgments do sum up the bearing of each and all of the nine on the questions in hand, and every moral judgment sums up the bearing of one or more of the requirements". FINNIS, John. Natural Law \& Natural Rights. $2^{\text {nd }}$ ed. Oxford: Oxford University Press, 2011, p. 126.

${ }^{110}$ Cf. FINNIS, John. Natural Law \& Natural Rights. $2^{\text {nd }}$ ed. Oxford: Oxford University Press, 2011.

${ }^{111}$ Cf. FINNIS, John. Natural Law \& Natural Rights. $2^{\text {nd }}$ ed. Oxford: Oxford University Press, 2011. 
responsabilidade civil. ${ }^{112}$

O ponto de partida para compreensão do bem comum é o que Finnis denomina de comunidades como tipos de relações unificadoras. ${ }^{113}$ Além da confusão terminológica, Finnis remonta às ordens do conhecimento em São Tomás de Aquino para sistematizar as relações unificadoras a partir de tipos de ordens, sendo elas: a) ordem das ciências naturais (falantes e ouvintes se relacionam por sua capacidade natural de escutar e falar); b) a ordem lógica, epistemológica, metodológica, etc. (relacionada ao conhecimento ele mesmo, um grupo de pessoas pode se reunir para discutir sobre a essência da razão); c) a ordem da consciência estética (aquilo que nos apropriamos e moldamos a partir de nós mesmos, presente nas artes) e; d) a ordem da ética (voltada para a compreensão e uniformização do nosso agir). ${ }^{114} \mathrm{~A}$ última ordem é a mais relevante para fins da investigação da tese em apreço.

Nesse sentido, a intencionalidade da associação presume, obrigatoriamente, a compreensão da finalidade da associação. Logo, Finnis admite que as comunidades possam ser formadas a partir de três intenções distintas: a) por interesse em "negócios"; b) por interesse no "jogo" e; c) por interesse na "amizade". ${ }^{115}$ Um professor pode escolher se associar aos seus alunos por conta do interesse no negócio "ensinar". Ele receberá uma contraprestação de seus estudantes em troca da obrigação de prestar um determinado serviço. Da mesma forma, um jogador de xadrez pode escolher se associar a outros jogadores pelo simples interesse em desenvolver um jogo. O mesmo funcionaria para outras modalidades de jogos, como, por exemplo, o jogo linguístico. ${ }^{116}$ Esses tipos de comunidade são baseadas na exploração e equalização das vontades individuais e sua inter-relação. Justamente o que se presencia no direito brasileiro sob a alcunha de teoria da responsabilidade.

Numa comunidade por negócios ou jogos é imperioso que o participante se amolde às exigências objetivas das regras se tornando responsável por suas ações (e somente por elas) no limite do que lhe é

112 Cf. FINNIS, John. Natural Law \& Natural Rights. $2^{\text {nd }}$ ed. Oxford: Oxford University Press, 2011.

${ }^{113}$ FINNIS, John. Natural Law \& Natural Rights. $2^{\text {nd }}$ ed. Oxford: Oxford University Press, 2011, p. 135.

114 FINNIS, John. Natural Law \& Natural Rights. $2^{\text {nd }}$ ed. Oxford: Oxford University Press, 2011, p. 135-138.

${ }^{115}$ FINNIS, John. Natural Law \& Natural Rights. $2^{\text {nd }}$ ed. Oxford: Oxford University Press, 2011, p. 139.

${ }^{116}$ FINNIS, John. Natural Law \& Natural Rights. $2^{\text {nd }}$ ed. Oxford: Oxford University Press, 2011, p. 139. 
exigido pelas regras do negócio, ou pelas regras do jogo. Esta é a falha essencial apontada no tópico anterior sobre o não positivismo inclusivo: a carência de uma teoria ética relativiza o propósito de uma investigação a respeito do que vem a ser a responsabilidade civil e admite como pressuposto essencial que as comunidades para as quais se voltam as teses jurídicas são constituídas por interesses em realização de negócios ou de jogos. A resposta de Finnis para esse problema reside na tese aristotélica da compreensão das comunidades a partir da "amizade" (friendship), argumentando ele sobre a disposição de como funcionaria uma tal sociedade a partir do seguinte argumento:

If $\mathrm{A}$ and $\mathrm{B}$ are friends, then the collaboration of each is for the sake (at least in part) of the other, and there is community between them not only in that there is a common interest in the conditions, and common pursuit of the means, whereby each will get what he wants for himself, but also in that what A wants for himself he wants (at least in part) under the description "that-which-Bwants-for-himself", and vice versa. Indeed, the good that is common between friends is not simply the good of successful collaboration or co-ordination, nor is it simply the good of two successfully achieved coinciding projects or objectives; it is the common good of mutual self-constitution, self-fulfillment, self-realization. ${ }^{117}$

Essa é uma parte da essência do bem comum. Daí a conclusão lógica de Finnis sobre a metáfora da família como tipo de comunidades completas, onde os participantes dessa comunidade tomam para si como metas de realização de seu bem-estar o bem-estar do próximo. ${ }^{118}$ Onde estaria, então, o conceito completo de bem comum a partir de Finnis? ${ }^{119}$ Para ele, o bem comum é um conceito genérico, ele só pode ser alcançado como postulado ético se se considerar a comunidade constituída a partir da amizade, ou seja, da associação presume-se a boa-fé objetiva entre os objetivos e as ações dos concidadãos; de outra sorte, Finnis admite que a compreensão do bem comum na execução de uma determinada ação

117 FINNIS, John. Natural Law \& Natural Rights. $2^{\text {nd }}$ ed. Oxford: Oxford University Press, 2011, p. 141.

${ }^{118}$ FINNIS, John. Natural Law \& Natural Rights. $2^{\text {nd }}$ ed. Oxford: Oxford University Press, 2011, p. 147.

${ }^{119}$ Cf. FINNIS, John. Natural Law \& Natural Rights. $2^{\text {nd }}$ ed. Oxford: Oxford University Press, 2011. 
depende, também, das exigências de razoabilidade prática. ${ }^{120}$ Desse modo, a partir da tese finnisiana a responsabilidade jurídica poderia ser ressignificada a partir de uma teoria ética completa e adequada para um conceito inclusivo de direito.

\section{CONCLUSÃO}

O sistema de responsabilidade baseado num liberalismo kantiano está realmente fadado ao insucesso? $O$ que há de se esperar da responsabilidade civil a partir de uma teoria ética? Quais os problemas do jusnaturalismo finnisiano e sua aplicabilidade no Brasil? Bem, essas questões são problemas subjacentes ao propósito desta tímida investigação, mas que estão diretamente ligados ao ponto onde a teoria se encontra com a prática. Uma pesquisa acadêmica não deve se limitar ao escopo das averiguações científicas e deve buscar, incessantemente, a sua realização prática, como sempre nos ensina a professora Pastora Leal. Infelizmente, neste artigo, pela limitação de tempo e espaço, nós vamos nos ater às questões teórico-filosóficas que foram apresentadas ao longo desse desenvolvimento. Porém, achamos prudente a continuação dessa pesquisa no futuro para mensurar os efeitos práticos da admissão da necessidade de reconfiguração da responsabilidade civil a partir da ética naturalista. Em síntese, estes foram os pontos centrais da discussão apresentada:

a. A teoria do não positivismo inclusivo de Robert Alexy admite a necessária conexão entre direito e moral como critério qualitativo do direito (só é direito aquilo que possuí um pano de fundo moral);

b. O argumento da injustiça a partir da fórmula Radbruch é a fórmula utilizada por Alexy para atribuir essa qualidade às normas jurídicas;

c. Alexy admite a conexão entre sua teoria do direito (tanto no

${ }^{120}$ FINNIS, John. Natural Law \& Natural Rights. $2^{\text {nd }}$ ed. Oxford: Oxford University Press, 2011, p. 154. 
Conceito e Validade do Direito ${ }^{121}$ quanto na Teoria dos Direitos Fundamentais 122 ) com a teoria do discurso e a teoria da argumentação jurídica;

d. A aplicação do direito depende da prática discursivoargumentativa e se formaliza a partir da aplicação das regras do discurso, o que gera, outrossim, um relativismo no ato de aplicar o direito;

e. Para responsabilidade civil, isso significa admitir a relatividade do reconhecimento de configuração da própria responsabilidade e, conseguintemente, do próprio dano.

f. Uma alternativa para mitigar o relativismo é a teoria do jusnaturalismo revigorado de Finnis que propõe:

1. Uma crítica metodológica às teorias sociais e descritivas do direito;

2. Uma teoria ético-política para o reconhecimento e aplicação do direito;

3. O reconhecimento da existência de um conjunto de bens humanos básicos;

4. O reconhecimento da existência de um conjunto de requisitos de razoabilidade prática;

5. Uma teoria jurídica adequada às exigências do reconhecimento de bens humanos básicos e dos requisitos de razoabilidade prática.

g. A ideia de comunidades formadas por amizade e a compreensão do bem comum como sendo atingível a partir da ética e dos requisitos de razoabilidade prática se torna um caminho para mitigar a tese relativista a respeito da reconfiguração e do reconhecimento da responsabilidade e do dano.

${ }^{121}$ ALEXY, Robert. Conceito e Validade do Direito. Org. Ernesto Garzón Valdés;

Hartmut Kleimt; Lothar Kuhlen; Ruth Zimmerling. Trad. Gercélia Batista de Oliveira Mendes. $1^{\mathrm{a}}$ ed. $2^{\mathrm{a}}$ tir. São Paulo, SP: WMF Martins Fontes, 2011.

${ }^{122}$ ALEXY, Robert. Teoria dos Direitos Fundamentais. Trad. Virgílio Afonso da Silva. São Paulo, SP: Malheiros, 2008. 
Alieksiéi Fiódorovitch Karamázov, personagem do livro Irmãos Karamázov de Fiodor Dostoiéviski, numa determinada passagem do texto sentencia a seguinte frase: "somos todos culpados de tudo e de todos, e eu mais do que todos os outros". ${ }^{123}$ Não admitir sua responsabilidade para com o outro é somente enxergar a si mesmo e medir os reflexos de suas condutas a partir de seus interesses específicos na interação social constituída por uma pluralidade de "eus". Reconhecer sua parcela de responsabilidade no agir do outro é, consideravelmente, um ganho ético que não pertence a um "eu", mas a um infinito particular compartilhado por todos. A ética se torna o a priori da própria filosofia. Essa é, por exemplo, a proposição levinásiana. ${ }^{124}$

Se há realmente um caminho para a conversão do agir em prol do outro, esse não pode existir fora da ética. Por isso, as teorias jurídicas que pregam a tese de separabilidade não possuem uma adequada recepção dentro da tradição jurídica brasileira e nos esforçamos em compreender como pode uma teoria jurídica social, descritiva ou normativa, não conceber uma análise sobre o agir ético? A teoria de Finnis, apesar de possuir os seus êxitos, em especial nesse sentido (o diálogo com a tradição "inclusivista" no Brasil), possui também suas falhas e, logicamente, incoerências no discurso poderiam ser apontadas por um leitor que discorde de tal tese e seus reflexos sobre a reconfiguração da responsabilidade. ${ }^{125}$

Qual o caráter ético dos animais não humanos? A família é um bem humano básico? Como aplicar essa teoria ética num cenário internacional? A teoria de Finnis não se tornou um discurso velado de retorno a um conservadorismo cristão antiliberal? ${ }^{126}$ São várias questões levantadas contra o jusnaturalismo revigorado em Lei Natural e Direitos Naturais. ${ }^{127}$ Porém, argumentamos em sede de conclusão: como seria possível descartar a teoria do jusnaturalismo revigorado de Finnis sem

${ }^{123}$ DOSTOIÉVISKI, Fiodor. Os Irmãos Karamazov. Trad. Paulo Bezerra. São Paulo, SP: Ed. 34, 2008, p. 396.

${ }^{124}$ LÉVINAS, Emmanuel. Entre nós: ensaios sobre a alteridade. Trad. Pergentino Stefano Pivatto. Petrópolis, RJ: Vozes, 1997, p. 148.

${ }^{125}$ Cf. FINNIS, John. Natural Law \& Natural Rights. $2^{\text {nd }}$ ed. Oxford: Oxford University Press, 2011.

${ }^{126}$ Cf. FINNIS, John. Natural Law \& Natural Rights. $2^{\text {nd }}$ ed. Oxford: Oxford University Press, 2011.

${ }^{127}$ Cf. FINNIS, John. Natural Law \& Natural Rights. $2^{\text {nd }}$ ed. Oxford: Oxford University Press, 2011. 
primeiro tentar compreendê-la? ${ }^{128}$

No que tange à responsabilidade, para nós fica claro o caminho (a via alternativa) que pode ser tomado pela teoria: uma filosofia da responsabilidade pautada pela ética e pelo bem comum parece ser a mais adequada num cenário de supervalorização do "eu". Pode-se discutir, além da inserção do interesse jurídico (através do bem comum), o caráter retributivo, punitivo, existencial do ato "responsabilizar alguém por alguma coisa". Porém, admitimos que este estudo seja ainda embrionário e necessita de um desenvolvimento prático, analisando, discutindo e criticando decisões judiciais e casos jurídicos que podem servir de experimento para comprovação dessa tese.

Em tempo, gostaríamos de agradecer imensamente a duas pessoas que contribuíram em demasiado para realização desta pesquisa. Primeiramente, ao Professor Dr. Victor Sales Pinheiro, não só pela introdução, lições e aulas sobre o pensamento finnisiano, mas especialmente pela amizade (num sentido aristotélico) e pelo exemplo de coragem ao levantar a vanguarda da bandeira do jusnaturalismo na região amazônica. Ele constitui um legítimo exemplo do emprego das virtudes cardeais. Por fim, e não menos importante, ao Professor Ms. Alexandre Bonna, que, além de ter discutido conosco alguns insights para a escrita do artigo e presidir um grupo de pesquisa com a temática, sei que, pela amizade (também num sentido aristotélico) retornará, dialeticamente, aos argumentos levantados neste texto.

\section{REFERÊNCIAS}

ALEXY, Robert. Conceito e Validade do Direito. Org. Ernesto Garzón Valdés; Hartmut Kleimt; Lothar Kuhlen; Ruth Zimmerling. Trad. Gercélia Batista de Oliveira Mendes. $1^{\underline{a}}$ ed. $2^{\underline{a}}$ tir. São Paulo, SP: WMF Martins Fontes, 2011.

${ }^{128}$ Cf. FINNIS, John. Natural Law \& Natural Rights. $2^{\text {nd }}$ ed. Oxford: Oxford University Press, 2011. 
. Human Dignity and Proportionality Analysis. Espaço Jurídico

Journal of Law, Vol. 16, 3 (Edição Especial), 2016.

. Teoria da Argumentação Jurídica: a Teoria do Discurso

Racional como Teoria da Fundamentação Jurídica. Trad. Zilda

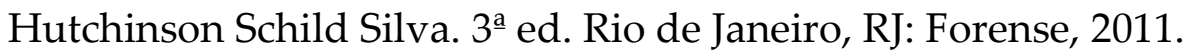

. Teoria Discursiva do Direito. Trad. e Org. Alexandre

Travessoni Gomes Trivisonno. Rio de Janeiro, RJ: Forense Universitária, 2014.

. Teoria dos Direitos Fundamentais. Trad. Virgílio Afonso da Silva. São Paulo, SP: Malheiros, 2008.

FINNIS, John. Human Rights and Common Good. Collected Essays: Volume III. Oxford: Oxford University Press, 2011.

. Natural Law \& Natural Rights. $2^{\text {nd }}$ ed. Oxford: Oxford University Press, 2011.

. Philosophy of Law. Collected Essays: Volume IV. Oxford:

Oxford University Press, 2011.

KELSEN, Hans. Teoria Pura do Direito. Trad. João Batista Machado. $8^{\mathrm{a}}$ ed. São Paulo, SP: Martins Fontes, 2009.

LÉVINAS, Emmanuel. Entre nós: ensaios sobre a alteridade. Trad. Pergentino Stefano Pivatto. Petrópolis, RJ: Vozes, 1997.

WITTGENSTEIN, Ludwig. Investigações Filosóficas. Trad. Marcos Montagnoli. 9ae ed. Petrópolis, RJ: Editora Vozes, 2014. 
O Argumento da Responsabilidade: um ensaio sobre o Não Positivismo Inclusivo de Robert Alexy e sobre os Bens Humanos Básicos The Argument from Accountability: an essay over the Robert Alexy's Inclusive Non-Positivism and Basic Human Goods Submetido em: 2017-07-28 Aceito em: 2017-12-27 